\title{
Combination of Reverse Transcription and Multienzyme Restriction Fragment Length Polymorphism Analysis for Rapid Detection of Escherichia Coli
}

\author{
Akifumi Hosoda $^{1 *}$, Arata Komaba ${ }^{2}$, Michiru Kishimoto ${ }^{2}$ and Hiroto Tamura ${ }^{1}$ \\ ${ }^{1}$ Department of Environmental Bioscience, Faculty of Agriculture, Meijo University, Japan \\ ${ }^{2}$ Department of Nutritional Sciences, School of Nutritional Sciences, Nagoya University of Arts and Sciences, Japan
}

\begin{abstract}
Cultivation methods are used to monitor pathogenic microorganisms in foods. However, the current methods require a few days to produce results, and products are often released for sale before the results of microbiological analysis become available. We developed an RNA extraction and microorganism detection system using model food samples inoculated with Escherichia coli K-12 and O157:H7 (GTC 14536) (0 CFU/g and $1 \times 10^{1}-10^{4} \mathrm{CFU} / \mathrm{g}$ ). Before RNA extraction, live or dead cells were inoculated into the food samples, the samples were homogenized, and the extracted RNAs were used to synthesize cDNAs using random 6-mer. PCR was used to analyze the target genes, and the PCR products were digested with two restriction enzymes (Hhal and HaellI) to analyze restriction fragment length polymorphism (RFLP). PCR confirmed the RNA extraction and CDNA synthesis of up to $1 \times 10^{1} \mathrm{CFU} / \mathrm{g}$ samples of live cells. Multienzyme RFLP (MeRFLP) showed that the sizes of the DNA fragments obtained were consistent with the theoretical fragment sizes, suggesting that reverse transcription-MeRFLP (RT-MeRFLP) could identify the target bacteria. These results suggest that RT-MeRFLP, which does not require culture and can be completed within $6.5 \mathrm{~h}$, is a promising approach for a low-cost, rapid, and reliable system for identifying bacteria in food.
\end{abstract}

Keywords: RNA extraction; cDNA; PCR; Multienzyme restriction fragment length polymorphism (ME-RFLP)

\section{Introduction}

Foodborne illnesses caused by pathogenic bacteria or viruses are among the most serious public health concerns worldwide. The ubiquitous and virulent nature of bacterial pathogens, such as Escherichia coli O157:H7, Staphylococcus aureus, Salmonella spp., and Campylobacter spp., creates a need for specific, sensitive, and rapid detection techniques [1]. The inspection of foods is essential when evaluating food safety and sanitation, and must be performed with appropriate stringency. In Japan, food is inspected by a traditional "official method" determined by the Ministry of Health, Labor and Welfare as part of the Food Sanitation Act [2]. This official method includes detection techniques that involve culturing bacteria or using immunological assays.

Culture techniques distinguish bacteria by their ability to grow on different media. However, positive identification cannot be confirmed by growth on a specific medium alone because many enteric bacteria possess similar biochemical characteristics. A different culture medium is often used for confirmation, which increases the analysis time. Because pathogenic bacteria are often present in very low numbers, several plates may be needed to streak the entire sample and incubate for the required time [3]. Moreover, the simultaneous detection and identification of pathogens by culturing different media plates can be difficult [4].

Nucleic acid-based methods have been replacing these traditional methods to identify, detect, and type pathogenic microorganisms in food products. Several approaches have been tried to overcome the limitations of the traditional methods such as their low sensitivity, accuracy, and effectiveness in identifying pathogens within complex target food matrices. These new methods must be validated and standardized to become reference methods [5].

Polymerase chain reaction (PCR) is a powerful nucleic acid-based tool to detect and identify bacteria, but it cannot distinguish between DNA from viable cells and that from dead cells. In addition to the ethidium monoazide bromide PCR method, reverse-transcription PCR (RT-PCR) can differentiate between viable and dead bacteria because most mRNAs have short half-lives in dead bacteria. Although RT-PCR is time consuming and requires high-quality mRNA, which can be difficult to extract [6], the reproducibility of RT-PCR is crucial for differentiating viable cells from dead cells $[7,8]$. Nucleic acid-based identification of bacterial phylogeny allows the differences between isolated bacterial floras to be compared more easily using restriction fragment length polymorphism (RFLP) analysis of amplified specific DNA fragments, such as terminal restriction fragment length polymorphism (T-RFLP) [9]. Amplified rDNA restriction analysis (ARDRA) is also one of the earliest techniques that 16S rRNA gene fragments are amplified by PCR and digested with different restriction enzymes to give patterns for each genospecies [10-13]. ARDRA with multiple enzyme restriction fragment length polymorphism (MeRFLP) provides more precise information about the differentiation based on microbial phylogeny and taxonomy, since digestion of amplicons with multiple restrection enzymes that provide several, unique restriction fragments that can be compared to robust sequence database [12-15].

*Corresponding author: Akifumi Hosoda, Department of Environmenta Bioscience, Faculty of Agriculture, Meijo University, 1-501 Shiogamaguch Tenpaku-ku, Nagoya City, Aichi 468-8502 Japan, Tel: +81-52-838-2522; Fax: +81 52-833-5524; E-mail: hosoda@meijo-u.ac.jp

Received October 15, 2013; Accepted December 02, 2013; Published Decembe 05, 2013

Citation: Hosoda A, Komaba A, Kishimoto M, Tamura H (2013) Combination of Reverse Transcription and Multienzyme Restriction Fragment Length Polymorphism Analysis for Rapid Detection of Escherichia Coli. J Microb Biochem Technol 6: 001-008. doi:10.4172/1948-5948.1000113

Copyright: $\odot 2013$ Hosoda A, et al. This is an open-access article distributed unde the terms of the Creative Commons Attribution License, which permits unrestricted use, distribution, and reproduction in any medium, provided the original author and source are credited 
Citation: Hosoda A, Komaba A, Kishimoto M, Tamura H (2013) Combination of Reverse Transcription and Multienzyme Restriction Fragment Length Polymorphism Analysis for Rapid Detection of Escherichia Coli. J Microb Biochem Technol 6: 001-008. doi:10.4172/1948-5948.1000113

The main aim of this study was to develop a method for rapid and simple bacterial RNA extraction from food samples. Phenol/guanidine isothiocyanate reagent and RNA extraction kits were used to evaluate both the RNA purity and detection limit for the bacteria analyzed. We aimed to evaluate methods to identify target bacteria using RT-PCR combined with MeRFLP based on 16S rRNA gene sequence.

\section{Materials and Methods}

\section{Bacteria and growth conditions}

Escherichia coli strain O157:H7 (GTC 14536) and K-12 were obtained from Escherichia coli strain K-12 was obtained from National Bioresource Project and Biological Resource Center at National Institute of Technology and Evaluation of Japan, respectively. The bacteria were streaked onto Luria-Bertani broth (LB) agar plates and incubated overnight at $37^{\circ} \mathrm{C}$. Single colonies were inoculated into $5 \mathrm{~mL}$ of liquid $\mathrm{LB}$ at $37^{\circ} \mathrm{C}$ with shaking at $100 \mathrm{rpm}$ overnight to produce a glycerol stock.

\section{Preparation of food samples contaminated by bacteria}

Sterilized sausages were selected as the model food sample and were obtained from Nippon Meat Packers Inc., Japan. The sterilized sausage $(25 \mathrm{~g})$ and saline solution $(225 \mathrm{~mL})$ were homogenized in a plastic bag for 1 min with a Masticator Basic (IUL SA Spain). Each sample of bacteria from the glycerol stock was grown in $50 \mathrm{~mL}$ of liquid $\mathrm{LB}$ in an Erlenmeyer flask at $37^{\circ} \mathrm{C}$ with shaking at $120 \mathrm{rpm}$ for $16 \mathrm{~h}$. The cells were harvested by centrifugation $(5,000 \mathrm{rpm}$ for 3 $\mathrm{min}$ ) and resuspended in $50 \mathrm{~mL}$ of diluted sterilized saline solution. After three washing cycles, the cells were diluted at $1 \times 10^{8} \mathrm{CFU} / \mathrm{mL}$ in sterilized saline solution. To confirm that only viable cells contained transcript of the target RNA, we included a dead cell control from 10 $\mathrm{mL}$ of $E$. coli cells $\left(\sim 10^{8}\right.$ cells $\left./ \mathrm{mL}\right)$ that had been autoclaved for $15 \mathrm{~min}$ at $121^{\circ} \mathrm{C}$. Each sample of live and dead cells was diluted serially $\left(1 \times 10^{1}\right.$ to $1 \times 10^{4} \mathrm{CFU} / \mathrm{g}$ ) and then inoculated into the model food samples. The dilution rate was confirmed by colony counting on LB agar plates. The all experiments listed below were repeated three times with triplicate samples.

\section{Total RNA extraction}

RNA extraction was performed in triplicate. Total RNA was extracted from $2 \mathrm{~mL}$ of diluted cells and from $2 \mathrm{~mL}$ of model food suspensions using a High Pure RNA isolation kit (Roche $\mathrm{GmbH}$, Germany) according to the manufacturer's instructions with a slight modification in which lysozyme was replaced by Proteinase K (10 $\mathrm{mg} / \mathrm{mL}$ ) for cell lysis. TRIzol (Invitrogen, USA), a phenol/guanidine isothiocyanate reagent, was also used for total RNA extraction from the same food suspensions. The concentration and purity of the extracted RNA were measured by UV absorption (Bio Spec-mini DNA/RNA/ protein analyzer, Shimadzu, Japan). The RNA extracts from diluted cells were found to have an A260/A280 ratio >1.6, and the ratios from the model food samples ranged from 1.0 to 1.8. The RNA samples were frozen immediately at $-80^{\circ} \mathrm{C}$ until use.

\section{Reverse transcription (RT)}

RT was performed to convert mRNA to cDNA using a High Capacity cDNA Reverse Transcription kit according to the manufacturer's procedures (Life Technologies). Total RNA was treated with DNase to remove any contaminating DNA and to ensure that only RNA was being amplified. Each $20 \mu \mathrm{L}$ reaction containing $100 \mathrm{ng}$ of total RNA, $2.0 \mu \mathrm{L}$ of $10 \times \mathrm{RT}$ random primers, $0.8 \mu \mathrm{L}$ of $25 \times \mathrm{dNTP}$ mix
(100 mM), $2.0 \mu \mathrm{L}$ of $10 \times \mathrm{RT}$ buffer, $1.0 \mu \mathrm{L}$ of RNase inhibitor, $1.0 \mu \mathrm{L}$ of MultiScribeTM Reverse Transcriptase, and Nuclease-free $\mathrm{H}_{2} \mathrm{O}$ up to a final volume of $20 \mu \mathrm{L}$ RT was performed in a TaKaRa PCR Thermal Cycler Dice (TaKaRa Bio, Japan) according to the manufacturer's instructions. A negative control containing all reagents except for the RNA template and a DNase control for each RNA template were also prepared.

\section{Quantitative PCR (qPCR) for primer fidelity}

To confirm the RT from RNA extraction and amplification efficiency of the primers used in the experiments, qPCR for enumerating the target bacterial gene copies was conducted on a StepOne plusTM Real-Time PCR system (Life Technologies, USA). A $20 \mu \mathrm{L}$ reaction mixture volume was used, and each reaction mixture contained $10 \mu \mathrm{L}$ Fast SYBR green Master Mix (Life Technologies), 7.6 $\mu \mathrm{L}$ sterile $\mathrm{H}_{2} \mathrm{O}$, $1.6 \mu \mathrm{L}$ DNA template, and $0.4 \mu \mathrm{M}$ each of the forward and reverse primers. Both 16S Rt-F (5'-ACTCCTACGGGAGGCAGCAG-3') and 16S Rt-R (5'-TTACCGCGGCTGCTGG-3') [13] primers were used to analyze the E. coli $16 \mathrm{~S}$ rRNA gene coding cDNA in the qPCR at $60^{\circ} \mathrm{C}$. The forward primer (41F) (5'-GCTCAGATTGAACGCTGGCG-3') corresponding to positions $22-41$ of the 16S rRNA gene of $E$. coli, which has $60 \%$ GC content, and the reverse primer (1066R) (5'-TGTAAAGTGTTGTGCTCGAC-3') corresponding to the positions $1,066-1,085$, which has $45 \%$ GC content [12]; were also used for qPCR at the same annealing temperature as used in the $16 \mathrm{~S}$ rRNA gene qPCR. The fragment sizes of the $16 \mathrm{~S}$ Rt- F-16S Rt-R and 41F-1066R primer sets were $197 \mathrm{bp}$ and $1070 \mathrm{bp}$, respectively. The amplification efficiency of both targets was around $100 \%$. The specificity of amplicons was also confirmed by DNA sequencing. Calibration of both genes was performed with serial dilutions of a known quantity of genomic DNA obtained from E. coli K-12. DNA copy numbers were calculated from the numbers of base pairs of genomic DNA using the average molecular weight of a base pair in double-stranded DNA $(660$ Da) [13].

\section{PCR for MeRFLP}

PCR was performed to amplify the target gene in the prepared cDNA samples. The PCR mixture $(25 \mu \mathrm{L})$ comprised nuclease-free $\mathrm{H}_{2} \mathrm{O}(14.6 \mu \mathrm{L}), 5 \times \mathrm{PCR}$ buffer $(5 \mu \mathrm{L}$ KAPA2G Fast PCR kit, KAPA Biosystems; USA), dNTP mixture (0.5 $\mu \mathrm{L}$ KAPA Biosystems), $5 \mathrm{U}$ of KAPA2G DNA polymerase (KAPA Biosystems), TaqRecA protein (0.4 $\mu$ g BioAcademia Co. Ltd, Japan), $10 \mathrm{mM}$ of ATP (1.0 $\mu \mathrm{L}$ TaKaRa, Japan), and $100 \mathrm{ng}$ of template cDNA. RecA protein from Thermus aquaticus (TaqRecA protein, BioAcademia, Japan) was used to promote precise priming at the sites where the primer sequence is completely complementary to that of the target sequence [15]. Both primers $41 \mathrm{~F}$ and $1066 \mathrm{R}$, with conserved V2 and V6 regions of the 16S rRNA gene, respectively, were used [12]. The reaction conditions were as follows: initial denaturation at $95^{\circ} \mathrm{C}$ for $1 \mathrm{~min}$, followed by 30 cycles at $95^{\circ} \mathrm{C}$ for $10 \mathrm{~s}, 50^{\circ} \mathrm{C}$ for $10 \mathrm{~s}$, and $72^{\circ} \mathrm{C}$ for $1 \mathrm{~s}$. The Dice Model TP600 thermal cycler (TaKaRa Bio) was used.

Each PCR product $(4 \mu \mathrm{L})$ was digested by 10 units of each restriction enzyme HhaI, and HaeIII (TaKaRa Bio) for $15 \mathrm{~min}$ at $37^{\circ} \mathrm{C}$. The resulting samples were then incubated at $70^{\circ} \mathrm{C}$ to inactivate the restriction enzymes.

Samples digested with each restriction enzyme were analyzed using a DNA 1000 kit on the Shimadzu MCE-202 MultiNA system (Shimadzu) in "on-tip analysis" mode. All sample runs were performed by the manufacturer. The running reagent comprised the reagent from 
Citation: Hosoda A, Komaba A, Kishimoto M, Tamura H (2013) Combination of Reverse Transcription and Multienzyme Restriction Fragment Length Polymorphism Analysis for Rapid Detection of Escherichia Coli. J Microb Biochem Technol 6: 001-008. doi:10.4172/1948-5948.1000113

the DNA 1000 kit separation buffer, DNA marker reagent; $60 \mathrm{ng}$ of $\phi X 174$ DNA/HaeIII markers (Promega) was added to each assigned ladder well. The digested DNA samples were placed into the MultiNA instrument alongside the running reagent. The samples and running reagents were mixed automatically on-tip and were analyzed using MultiNA Control and MultiNA Viewer software [16]. Theoretical restriction fragment patterns of $E$. coli were calculated by the NEBcutter v2.0 program [17].

\section{PCR for specific detection of cDNA from $E$. coli}

The reverse primer Eco-R (5'-GCGGGTAACGTCAATGAGCAAA-3') was designed for the specific detection of E. coli with $50 \%$ GC content. The forward primer was the $41 \mathrm{~F}$ primer mentioned above. The fragment size of the primer sets was $471 \mathrm{bp}$ for the E. coli $16 \mathrm{~S}$ rRNA gene. PCR was performed using cDNA mixed with E. coli or cDNA extracted from the strain using same reagents and reaction conditions as described in PCR for MeRFLP. MeRFLP analysis of amplicons was also performed using the method described in PCR for MeRFLP.

\section{Sequence analysis}

PCR amplicons corresponding to the expected size of 1070 and 471 bp were purified with a QIAquick PCR Purification Kit (Qiagen, CA, USA). The gene fragments were cloned into plasmids using the pGEM-T Easy vector system (Promega, WI, USA). Cloned amplicons were prepared from randomly selected recombinants and were used as templates for sequencing. Each clone was sequenced with the T7W and SP6W primers [18]. The gene fragments were sequenced with the $41 \mathrm{~F}$ and 1066R primers using the BigDye Terminator v3.1 kit (Life Technologies, CA, USA) and an automated sequence analyzer (ABI PRISM 3130xl Genetic Analyzer; Applied Biosystems, CA, USA). All sequences were checked for chimeric artifacts with the Chimera Check program in the Ribosomal Database Project II $[19,20]$ and were compared with similar sequences for reference organisms with a BLAST search [21]. The sequences reported in this paper have been deposited in the GenBank, EMBL, and DDBJ nucleotide sequence databases under GenBank/EMBL/DDBJ Accession Numbers AB844266 and AB844267.

\section{Results}

\section{RNA extraction and RT}

Several methods of RNA extraction, involving hot phenol/ guanidine isothiocyanate extraction and different chaotropic agents were tested. The most reproducible results were obtained when cells were extracted from food suspensions in a chaotropic buffer with the High Pure RNA Isolation kit (Roche). Since the TRIzol reagent did not extract any RNA from food samples, the spectroscopic data were not obtained. The quantity and quality of total bacterial RNA of both the K-12 and O157:H7 are summarized in Table 1. We obtained total RNA at concentrations of 2 to $15 \mathrm{ng} / \mu \mathrm{L}$ in both the live and dead cell samples. Although the quality of RNA (as shown by the A260/280 ratio) would be inappropriate for RNA analysis, synthesis of the cDNA was performed. We also extracted total RNAs from $E$. coli cells suspended serially in saline solution using the kit mentioned above. The quantity and quality of RNA from the suspended cells did not differ significantly from the results of food samples (data not shown). qPCR was used to analyze the cDNA synthesized from the RNAs shown in Table 1 and the DNase-treated control. The target $E$. coli gene copy numbers both the K-12 and O157:H7 determined in the synthesized cDNA are presented in Table 2. The copy number of target PCR products in the K-12 cDNAs amplified with each 41F-1066R and 41F-Eco-R primer set ranged from $4.22 \times 10^{0}$ to $9.59 \times 10^{2}$ and from $8.10 \times 10^{1}$ to $2.63 \times 10^{4}$ copies/ng cDNA, respectively (Table 2). In case of O157:H7, the copy numbers amplified with each 41F-1066R and 41F-Eco-R primer set were ranged from $6.24 \times 10^{3}$ to $6.83 \times 10^{4}$ and from $3.40 \times 10^{1}$ to $2.81 \times 10^{4}$ copies/ng cDNA, respectively (Table 2). The amplification efficiency of both targets was $100.6 \%$ and $79.6 \%$, respectively.

\section{PCR to detect and identify target bacteria}

To examine the limit of detection of the 41F-1066R primer set for subsequent analyses, we prepared total RNA from various cell numbers $\left(1 \times 10^{1}\right.$ to $\left.1 \times 10^{4} \mathrm{CFU} / \mathrm{g}\right)$ of $E$. coli $\mathrm{K}-12$ and $\mathrm{O} 157: \mathrm{H} 7$, respectively, and synthesized cDNA and PCR for MeRFLP. As shown in Figure 1A, the target gene (1070 bp) of K-12 was detected clearly at $1 \times 10^{3}$ and $1 \times 10^{4} \mathrm{CFU} / \mathrm{g}$ of cDNA from food samples inoculated with living cells. By contrast, no amplicons of cDNA derived from dead cells were detectable except for lane 7. The detection limit for the PCR of cDNA was $1 \times 10^{4} \mathrm{CFU} / \mathrm{g}$ of food sample. The same results were observed in O157:H7 (Figure 2A). The 41F-Eco-R primer set was also evaluated using serially diluted cDNA from samples containing E. coli $\mathrm{K}-12$. The PCR amplification deduced from K-12 cDNA was obtained from $1 \times 10^{1}$ to $1 \times 10^{4} \mathrm{CFU} / g$; there was no amplification of cDNAs from dead cells (Figure 3A). The same results were also observed in O157:H7 (Figure $4 \mathrm{~A})$. Thus, the detection limit for the PCR of cDNA was $1 \times 10^{1} \mathrm{CFU} / \mathrm{g}$ of food sample (Figures 3 and 4). When PCR without the RecA protein were conducted, no amplicons of cDNA were detected at $1 \times 10^{1}$ to $1 \times 10^{4} \mathrm{CFU} / g$ (data not shown).

\begin{tabular}{|c|c|c|c|c|}
\hline \multirow{2}{*}{$\mathrm{CFU} / \mathrm{g}$} & \multicolumn{2}{|c|}{ O157:H7 } & \multicolumn{2}{|c|}{$\mathrm{K}-12$} \\
\hline & Conc $(n g / \mu l)$ & Ratio of A260/280 & Conc (ng/ $\mu \mathrm{l})$ & Ratio of A260/280 \\
\hline Noncell control & $7.17 \pm 4.62$ & $1.44 \pm 0.24$ & $2.03 \pm 0.28$ & $1.75 \pm 0.19$ \\
\hline $1 \times 10^{1}$ Living cells & $2.73 \pm 1.15$ & $1.32 \pm 0.34$ & $10.4 \pm 4.58$ & $0.89 \pm 0.31$ \\
\hline $1 \times 10^{2}$ Living cells & $3.50 \pm 0.46$ & $1.49 \pm 0.08$ & $2.26 \pm 0.90$ & $1.51 \pm 0.09$ \\
\hline $1 \times 10^{3}$ Living cells & $3.30 \pm 0.53$ & $1.64 \pm 0.11$ & $7.78 \pm 3.76$ & $1.14 \pm 0.04$ \\
\hline $1 \times 10^{4}$ Living cells & $3.27 \pm 1.33$ & $1.80 \pm 0.75$ & $3.42 \pm 0.14$ & $1.51 \pm 0.13$ \\
\hline $1 \times 10^{6}$ Living cells & ND* & ND & $8.82 \pm 0.11$ & $1.82 \pm 0.04$ \\
\hline $1 \times 10^{1}$ dead cells & $2.47 \pm 0.04$ & $1.26 \pm 0.04$ & $15.4 \pm 3.79$ & $1.21 \pm 0.46$ \\
\hline $1 \times 10^{2}$ dead cells & $2.21 \pm 0.83$ & $1.20 \pm 0.03$ & $2.57 \pm 0.24$ & $1.65 \pm 0.02$ \\
\hline $1 \times 10^{3}$ dead cells & $3.07 \pm 0.31$ & $1.24 \pm 0.18$ & $6.74 \pm 0.54$ & $1.18 \pm 0.11$ \\
\hline $1 \times 10^{4}$ dead cells & $2.97 \pm 0.67$ & $1.54 \pm 0.15$ & $3.16 \pm 0.94$ & $1.43 \pm 0.03$ \\
\hline $1 \times 10^{6}$ dead cells & ND & ND & $4.57 \pm 1.21$ & $1.65 \pm 0.10$ \\
\hline
\end{tabular}

*because they are not determined 
Citation: Hosoda A, Komaba A, Kishimoto M, Tamura H (2013) Combination of Reverse Transcription and Multienzyme Restriction Fragment Length Polymorphism Analysis for Rapid Detection of Escherichia Coli. J Microb Biochem Technol 6: 001-008. doi:10.4172/1948-5948.1000113

\section{Identification of target bacteria by MeRFLP}

We confirmed the RFLP pattern of PCR products amplified from cDNAs with the 41F-1066R primer set after HhaI and HaeIII digestion. In the case of HhaI digestion, the PCR products obtained $\left(1 \times 10^{4} \mathrm{CFU} / \mathrm{g}\right.$ sample) were 203,366 , and $496 \mathrm{bp}$ fragments, indicating that cDNAs of E. coli K-12 were synthesized and amplified (Figure 1B). In the amplification of the cDNAs extracted from $E$. coli with the 41F-1066R primer set, the theoretical restriction fragment lengths of PCR products with HhaI were 197, 359, and 508 bp and with HaeIII were 25, 34, 156, $161,167,204$, and $317 \mathrm{bp}$. The results obtained from K-12 cDNAs inoculated into food samples were 203, 366, and 496 bp with HhaI, and 146,155, 159, 184, and 306 bp with HaeIII (Figures 1B, C and Table 3). In case of O157:H7, the observed fragments were 205, 372, and 491 bp with HhaI, and 160, 166, 167, 217, and 331 bp with HaeIII (Figures 2B, C and Table 3). Although the specific identification of $E$. coli using MeRFLP was demonstrated, the PCR amplicons obtained

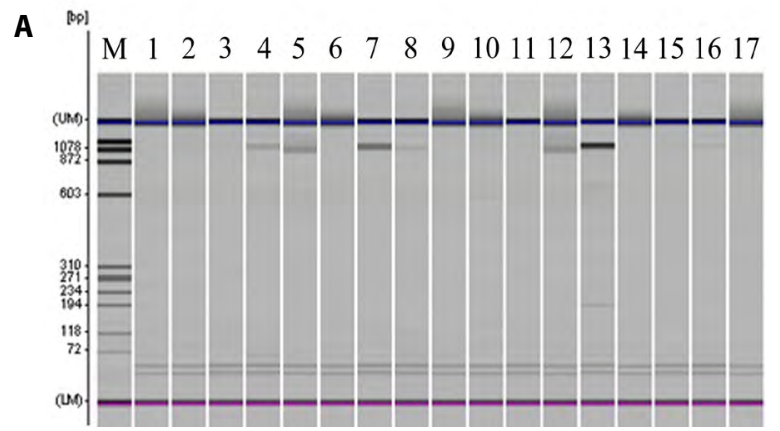

B
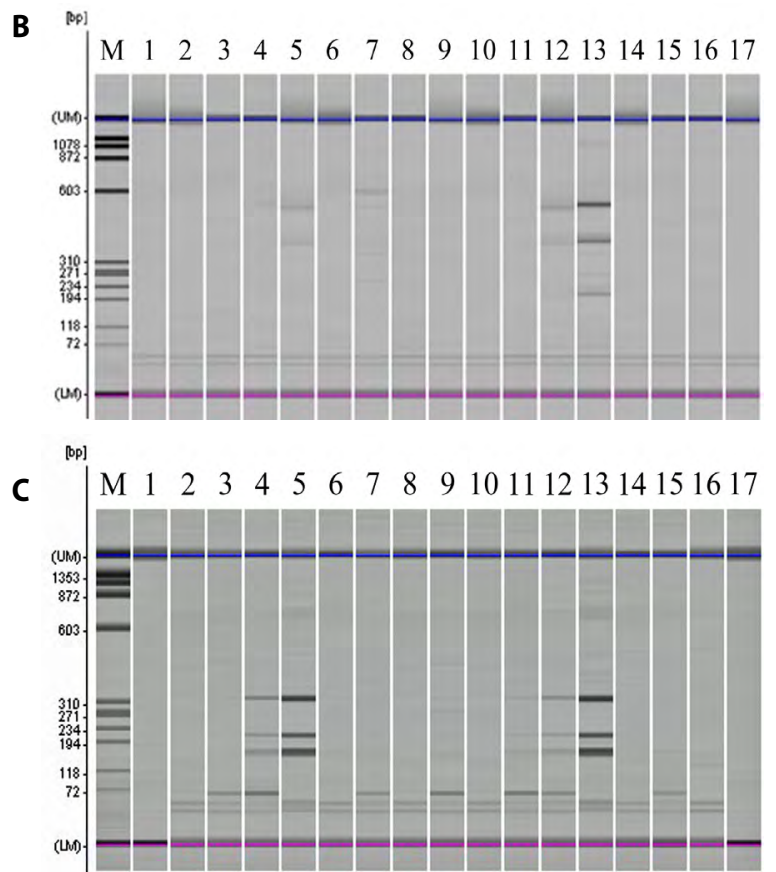

Figure 1: Microtip electrophoresis analysis of $(A) P C R$ product using the $41 \mathrm{~F}-1066 \mathrm{R}$ primer set and K-12 cDNA from food samples as templates, and (B) RT-MeRFLP digested with Hhal and (C) with Haell. Lane M: ladder marker; lane 1: $0 \mathrm{CFU} / \mathrm{g}$; lanes 2 and 10: live cells $1 \times 10^{1} \mathrm{CFU} / \mathrm{g}$; lanes 3 and 11: live cells $1 \times 10^{2} \mathrm{CFU} / \mathrm{g}$; lanes 4 and 12: live cells $1 \times 10^{3} \mathrm{CFU} / \mathrm{g}$; lanes 5 and 13: live cells $1 \times 10^{4} \mathrm{CFU} / \mathrm{g}$; lanes 6 and 14: dead cells $1 \times 101 \mathrm{CFU} / \mathrm{g}$; lanes 7 and 15: dead cells $1 \times 10^{2} \mathrm{CFU} / \mathrm{g}$; lanes 8 and 16: dead cells $1 \times 10^{3} \mathrm{CFU} / \mathrm{g}$; lanes 9 and 17: dead cells $1 \times 10^{4} \mathrm{CFU} / \mathrm{g}$.

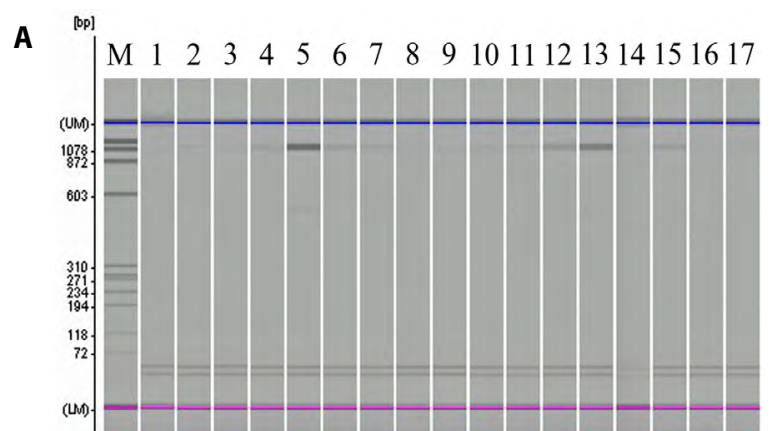

B

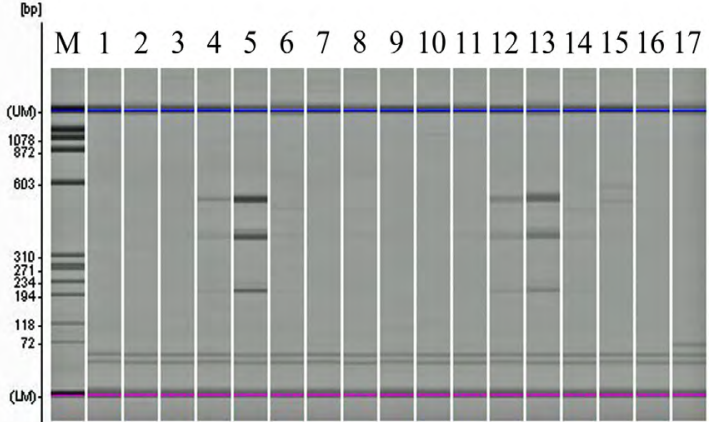

C

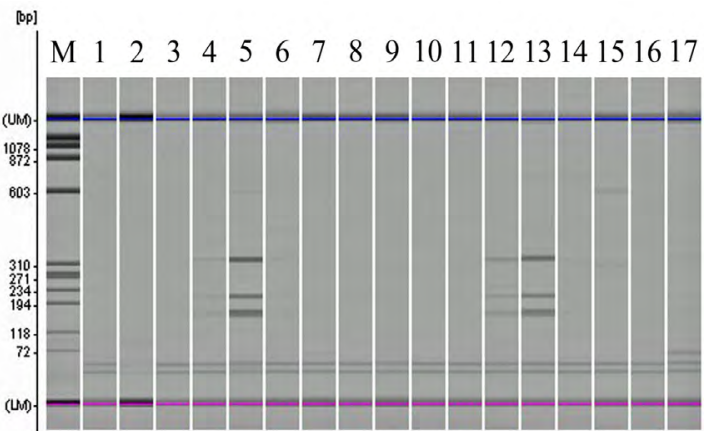

Figure 2: Microtip electrophoresis analysis of (A) PCR product using the 41F-1066R primer set and O157:H7 cDNA from food samples as templates, and (B) RT-MeRFLP digested with Hhal and (C) with Haelll. Lane M: ladder marker; lane 1: $0 \mathrm{CFU} / \mathrm{g}$; lanes 2 and 10: live cells $1 \times 10^{1} \mathrm{CFU} / \mathrm{g}$; lanes 3 and 11: live cells $1 \times 10^{2} \mathrm{CFU} / \mathrm{g}$; lanes 4 and 12: live cells $1 \times 10^{3} \mathrm{CFU} / \mathrm{g}$; lanes 5 and 13: live cells $1 \times 10^{4} \mathrm{CFU} / \mathrm{g}$; lanes 6 and 14 : dead cells $1 \times 10^{1} \mathrm{CFU} / \mathrm{g}$; lanes 7 and 15: dead cells $1 \times 10^{2} \mathrm{CFU} / \mathrm{g}$; lanes 8 and 16: dead cells $1 \times 10^{3} \mathrm{CFU} / \mathrm{g}$; lanes 9 and 17: dead cells $1 \times 10^{4} \mathrm{CFU} / \mathrm{g}$.

from dead cells cDNA were detected. (Lane 7 in Figure 1A). After the PCR product was digested with the restriction enzymes, the resulting DNA band patterns had dissipated (Lane 7 in Figure 1B). Thus, no false-positive results were obtained from food samples that did not contain the target. The specificity of another primer sets (41F-Eco-R) was also confirmed with model food samples that had been serially diluted and inoculated with both E. coli K-12 and O157:H7. PCR products with the 41F-Eco-R primer set containing K-12 and O157:H7 cDNAs used as templates were observed as a single band (471 and $464 \mathrm{bp}$ ) in samples of $1 \times 10^{1}$ to $1 \times 10^{4} \mathrm{CFU} / \mathrm{g}$, and no nonspecific band was observed, respectively (Figures $3 \mathrm{~A}$ and $4 \mathrm{~A}$ ). The amplified DNAs derived from $E$. coli should produce theoretical restriction fragment lengths of 112 and $359 \mathrm{bp}$ (HhaI), and 25, 75, 167, 167, and $204 \mathrm{bp}$ (HaeIII). The results obtained from the cDNAs from K-12 inoculated into food samples were 118 and $361 \mathrm{bp}$ with HhaI, and 89, 167, and 198 bp with HaeIII (Figures 3B, C and Table 4). In case of O157:H7, the observed fragments were 118 , and $372 \mathrm{bp}$ with HhaI, and 85,169 , 
Citation: Hosoda A, Komaba A, Kishimoto M, Tamura H (2013) Combination of Reverse Transcription and Multienzyme Restriction Fragment Length Polymorphism Analysis for Rapid Detection of Escherichia Coli. J Microb Biochem Technol 6: 001-008. doi:10.4172/1948-5948.1000113

\begin{tabular}{|c|c|c|c|c|}
\hline \multirow[t]{3}{*}{ (CFU/g) } & \multicolumn{2}{|c|}{ O157:H7 } & \multicolumn{2}{|c|}{$\mathrm{K}-12$} \\
\hline & \multicolumn{2}{|c|}{ Gene numbers (copies) } & \multicolumn{2}{|c|}{ Gene numbers (copies) } \\
\hline & $41 \mathrm{~F}-1066 \mathrm{R}$ & $41 F-E c o-R$ & $41 \mathrm{~F}-1066 \mathrm{R}$ & $41 F-E c o-R$ \\
\hline Noncell control & nd & nd & nd & $\mathrm{nd}^{*}$ \\
\hline $1 \times 10^{1}$ Living cells & nd & $34.0 \pm 15$ & $4.22 \pm 2$ & $81.0 \pm 9$ \\
\hline $1 \times 10^{2}$ Living cells & $6.24 \times 10^{3} \pm 2179$ & $119 \pm 29$ & $506 \pm 159$ & $111 \pm 23$ \\
\hline $1 \times 10^{3}$ Living cells & $6.95 \times 10^{3} \pm 1125$ & $0.73 \times 10^{3} \pm 137$ & $280 \pm 99$ & $3.43 \times 10^{3} \pm 101$ \\
\hline $1 \times 10^{4}$ Living cells & $(6.83 \pm 3.82) \times 10^{4}$ & $2.81 \times 10^{4} \pm 139$ & $959 \pm 313$ & $2.63 \times 10^{4} \pm 576$ \\
\hline $1 \times 10^{1}$ dead cells & nd & nd & nd & nd \\
\hline $1 \times 10^{2}$ dead cells & nd & nd & nd & nd \\
\hline $1 \times 10^{3}$ dead cells & nd & nd & nd & nd \\
\hline $1 \times 10^{4}$ dead cells & nd & nd & nd & nd \\
\hline
\end{tabular}

*because they are not detected

Table 2: Gene numbers in cDNA extracted from food samples inoculated with living or dead cells.

\begin{tabular}{|c|c|c|c|c|c|c|}
\hline \multirow[b]{2}{*}{ Restriction enzyme } & \multicolumn{2}{|c|}{ Theoretical fragment length (bp) } & \multicolumn{2}{|c|}{ Actual fragment length $(\mathrm{bp})$ of $\mathrm{O} 157: \mathrm{H} 7$} & \multicolumn{2}{|c|}{ Actual fragment length (bp) of K-12 } \\
\hline & Hha I & Hae III & Hha I & Hae III & Hha I & Hae III \\
\hline \multirow{7}{*}{ 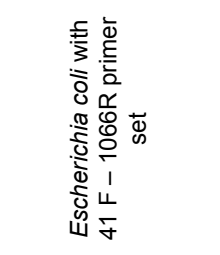 } & 508 & 317 & 491 & 331 & 496 & 306 \\
\hline & 359 & 204 & 372 & 217 & 366 & 184 \\
\hline & 197 & 167 & 205 & 167 & 203 & 159 \\
\hline & & 161 & & 166 & & 155 \\
\hline & & 156 & & 160 & & 146 \\
\hline & & 34 & & $\mathrm{nd}^{*}$ & & nd \\
\hline & & 25 & & nd & & nd \\
\hline
\end{tabular}

*because they were smaller than the lower limit of detection

Table 3: Theoretical and actual fragment length of PCR products amplified with the 41F-1066R primer set and digested with Hhal and Haell in E. coli.

and 216 bp with HaeIII (Figures 4B, C and Table 4). The lower limit of detection of the fragment length in this system was $<65 \mathrm{bp}$. Sequence analysis of the PCR products amplified with both primer sets showed that the corresponding sequences of E. coli were detected as observed in the MeRFLP analysis.

\section{Discussion}

Contamination of food by E. coli O157:H7 or other enteric bacteria such as $S$. aureus is an important public health concern. These bacteria are extremely virulent and can cause severe intestinal illness, and methods to detect and identify these bacteria are required for monitoring food supplies. Traditional detection methods, including the official method in Japan, are time consuming and costly. Many molecular techniques based on DNA analysis are not necessarily specific for detecting and identifying living cells. The present RTMeRFLP method, which combined cDNA synthesis and MeRFLP, was more specific and sensitive for detecting and identifying living bacterial in food samples.

In the case of RNA extraction using the High Pure RNA Isolation kit, spectroscopic observation of the RNA concentration showed that total RNA was extracted from the noncell controls. Since the Roche's kit was the specifications that can extract both animal and bacterial cells, in RNA extracting method, it is thought that the spectrophotometric data was able to obtain. However, the quantity of RNA isolated from food samples by the TRIzol reagent might be far lower [22]. This result may indicate the presence of nucleic acid residues (probably DNA) derived from food samples. PCR amplicons were detected using cDNA synthesized from the RNA from the inoculated cells, and the RNA concentration could be measured spectroscopically, whereas the cDNAs from the noncell control were not from the amplified target gene. Considering the stability of RNA in E. coli cells, these results support the idea that the cDNA obtained using the RNA extraction kit was synthesized from the total RNA from bacteria inoculated into the food samples [23].

Application of RecA protein to improve PCR fidelity was reported to overcome the difficulties amplifying with some DNA polymerases [15]. PCR using cDNA templates was performed with TaqRecA protein to improve the fidelity of the PCR primers. We chose a primer set that could amplify the $16 \mathrm{~S}$ rRNA gene as the target because this gene exists in high copy number in many bacteria [24]. The PCR products amplified with this primer set can be used for bacterial identification using MeRFLP analysis [12]. In the case of the 41F-1066R primer set, the cDNA synthesis and subsequent PCR detection limit was $1.0 \times 10^{4}$ $\mathrm{CFU} / \mathrm{g}$ in the present study, whereas a previous study reported a limit of $5.1 \times 10^{4} \mathrm{CFU} / \mathrm{g}$ in feces after $5 \mathrm{~h}$ incubation in culture media [25]. By contrast, the $41 \mathrm{~F}-\mathrm{Eco}-\mathrm{R}$ primer set could detect up to $1.0 \times 10^{1}$ CFU/g, indicating that multiple PCRs using both primer sets would help overcome the limitations in the detection and identification of the target bacteria. Although the amplification efficiency was lower for 41F-Eco-R than for 41F-1066R, a PCR product was obtained with the $41 \mathrm{~F}-\mathrm{Eco}-\mathrm{R}$ primer even from $\mathrm{CDNAs}$ at a concentration of $1.0 \times 10^{1}$ CFU/g. Furthermore, the present cDNA-based MeRFLP method detected only viable bacteria because PCR analysis of the food sample control inoculated with up to $1 \times 10^{4} \mathrm{CFU} / \mathrm{g}$ of pathogenic E. coli cells, that had been autoclaved at $121^{\circ} \mathrm{C}$ for $15 \mathrm{~min}$ before inoculation, detected no bands, suggesting that contaminated DNA did not cause any false-positive results.

Considering that high-percentage $\mathrm{G}+\mathrm{C}$ genes dissociate into singlestranded molecules with lower efficiency than do low-percentage $\mathrm{G}+\mathrm{C}$ templates, PCR primers may be easily annealed to the population of single-stranded molecules with low-percentage $\mathrm{G}+\mathrm{C}$ templates available for hybridization [26]. The $100 \mathrm{bp}$ sequences containing the reverse primer, Eco- $\mathrm{R}$ had a $50 \%$ GC content, whereas the sequences containing $1066 \mathrm{R}$ had a $55 \%$ GC content. (data not shown). In 
Citation: Hosoda A, Komaba A, Kishimoto M, Tamura H (2013) Combination of Reverse Transcription and Multienzyme Restriction Fragment Length Polymorphism Analysis for Rapid Detection of Escherichia Coli. J Microb Biochem Technol 6: 001-008. doi:10.4172/1948-5948.1000113

addition to the $\mathrm{G}+\mathrm{C}$ content of the template DNAs, we focused on the secondary structure of $16 \mathrm{~S}$ rRNA. Gutell, Woese et al. noted that the bases that are not paired in $16 \mathrm{~S}$ rRNA are accessible to enzymes such as nucleases or kinases $[27,28]$. The actual annealing position of Eco-R corresponded to $450-471$ bp of the $16 \mathrm{~S}$ rRNA gene of $E$. coli, and unpaired bases are abundant in this position. These data are consistent with the observation that the 41F-Eco-R primer set used in the present study had an advantage for $16 \mathrm{~S}$ rRNA gene amplification of the cDNA extracted from the food samples.

We used the Primer-BLAST program at the National Center for Biotechnology Information [29] to evaluate whether the primer set corresponding to the 16S rRNA gene of $E$. coli used in this study could amplify nonspecific genes in food samples. The data from the $41 \mathrm{~F}-1066 \mathrm{R}$ primer set for the $16 \mathrm{~S}$ rRNA gene showed that no amplification of genes from pig, chicken, plants (rice, maize, and soy bean) was observed,

A

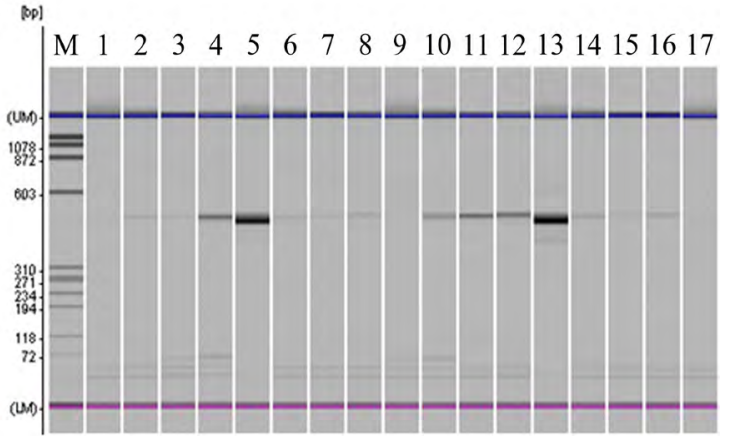

B

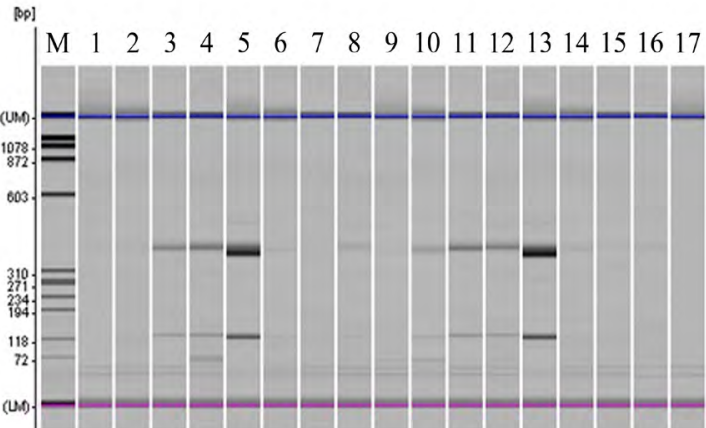

C $[\mathrm{pp}]$

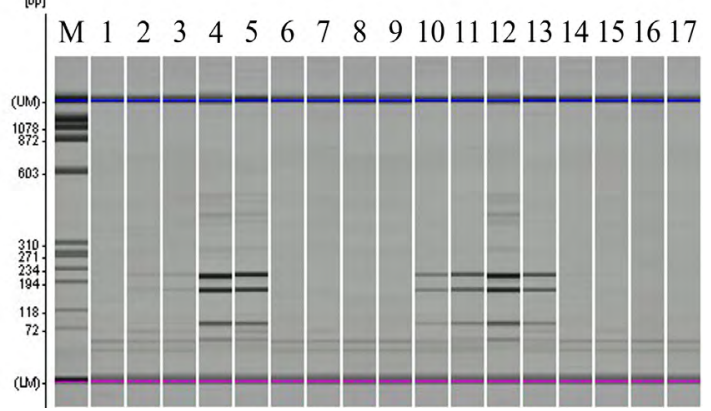

Figure 3: Microtip electrophoresis analysis of $\mathrm{PCR}$ product using the $41 \mathrm{~F}-$-Eco-R primer set, (A) K-12 cDNA from food samples as templates, and (B) RT-MeRFLP digested with Hhal and (C) with Haelll. Lane M: ladder marker lanes 1: $0 \mathrm{CFU} / \mathrm{g}$; lanes 2 and 10: live cells $1 \times 10^{1} \mathrm{CFU} / \mathrm{g}$; lanes 3 and 11: live cells $1 \times 10^{2} \mathrm{CFU} / \mathrm{g}$; lanes 4 and 12: live cells $1 \times 10^{3} \mathrm{CFU} / \mathrm{g}$; lanes 5 and 13 : live cells $1 \times 10^{4} \mathrm{CFU} / \mathrm{g}$; lanes 6 and 14: dead cells $1 \times 10^{1} \mathrm{CFU} / \mathrm{g}$; lanes 7 and 15 : dead cells $1 \times 10^{2} \mathrm{CFU} / \mathrm{g}$; lanes 8 and 16 : dead cells $1 \times 10^{3} \mathrm{CFU} / \mathrm{g}$; lanes 9 and 17: dead cells $1 \times 10^{4} \mathrm{CFU} / \mathrm{g}$.

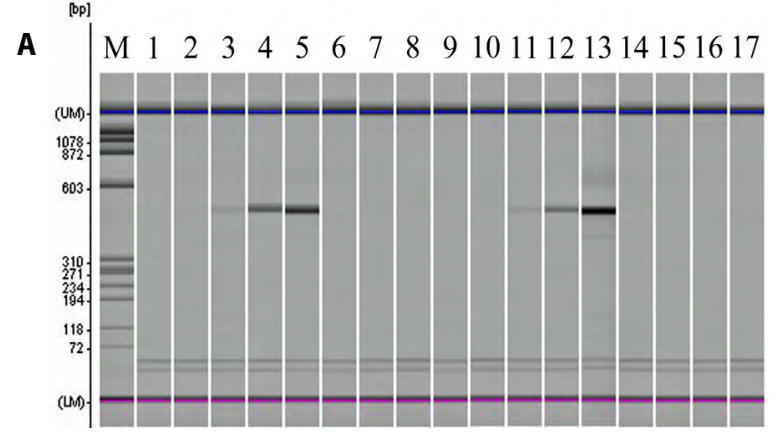

B

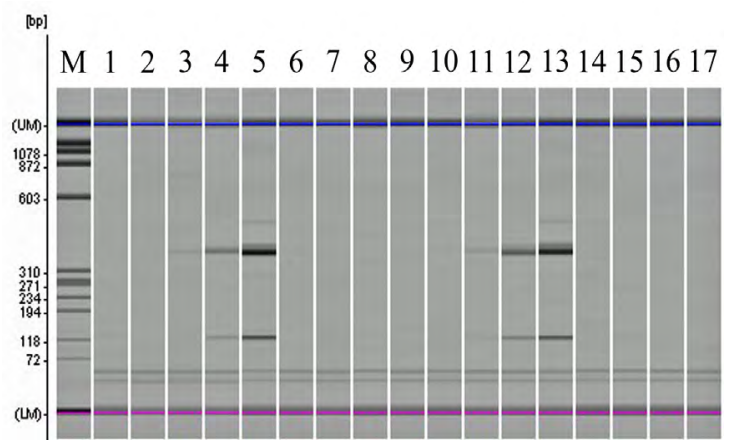

C

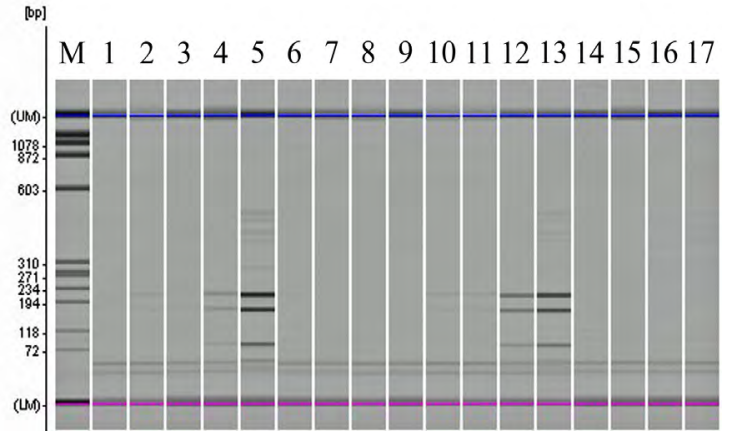

Figure 4: Microtip electrophoresis analysis of $\mathrm{PCR}$ product using the 41F-Eco-R primer set, (A) O157:H7 cDNA from food samples as templates, and (B) RT-MeRFLP digested with Hhal and (C) with Haelll. Lane M: ladder marker; lanes 1: $0 \mathrm{CFU} / \mathrm{g}$; lanes 2 and 10: live cells $1 \times 10^{1} \mathrm{CFU} / \mathrm{g}$; lanes 3 and 11: live cells $1 \times 10^{2} \mathrm{CFU} / \mathrm{g}$; lanes 4 and 12: live cells $1 \times 10^{3} \mathrm{CFU} / \mathrm{g}$; lanes 5 and 13: live cells $1 \times 10^{4} \mathrm{CFU} / \mathrm{g}$; lanes 6 and 14: dead cells $1 \times 10^{1} \mathrm{CFU} / \mathrm{g}$; lanes 7 and 15: dead cells $1 \times 10^{2} \mathrm{CFU} / \mathrm{g}$; lanes 8 and 16 : dead cells $1 \times 10^{3} \mathrm{CFU} / \mathrm{g}$; lanes 9 and 17: dead cells $1 \times 10^{4} \mathrm{CFU} / \mathrm{g}$.

whereas cow, and fruit fly nonspecific amplification was detected. In the case of the 41F-Eco-R primer set, no amplification of cow, pig, plants, or fruit fly was observed, although chicken nonspecific amplification was detected (data not shown).

Considering the resolution of microtip electrophoresis, the permission of error for the MeRFLP is up to $10 \%[12,30]$. Thus, the results shown from Figures $1 \mathrm{~B}, \mathrm{C}$ to Figure $4 \mathrm{~B}, \mathrm{C}$ are adequate to identify the target bacteria. In the case of $41 \mathrm{~F}-1066 \mathrm{R}$ primer set, the fragment sizes after treatment with HhaI were consistent with the theoretical fragmentation of the $16 \mathrm{~S}$ rRNA gene of E. coli K-12 and O157:H7. The fragmentation of cDNA with HaeIII also corresponded to that of the theoretical fragmentation (Table 3). PCR amplification by cDNA from dead cells $\left(1 \times 10^{2} \mathrm{CFU} / \mathrm{g}\right.$ sample) was detected, but no band patterns corresponding to $E$. coli $16 \mathrm{~S}$ rRNA gene digestion were observed. In the case of 41F-Eco-R primer set, both PCR products 
Citation: Hosoda A, Komaba A, Kishimoto M, Tamura H (2013) Combination of Reverse Transcription and Multienzyme Restriction Fragment Length Polymorphism Analysis for Rapid Detection of Escherichia Coli. J Microb Biochem Technol 6: 001-008. doi:10.4172/1948-5948.1000113

\begin{tabular}{|c|c|c|c|c|c|c|}
\hline \multirow[b]{2}{*}{ Restriction enzyme } & \multicolumn{2}{|c|}{ Theoretical fragment length (bp) } & \multicolumn{2}{|c|}{ Actual fragment length $(\mathrm{bp})$ of $\mathrm{O} 157: \mathrm{H} 7$} & \multicolumn{2}{|c|}{ Actual fragment length (bp) of K-12 } \\
\hline & Hha I & Hae III & Hha I & Hae III & Hha I & Hae III \\
\hline \multirow{4}{*}{ 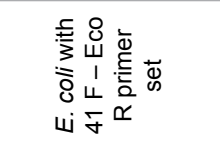 } & 359 & 204 & 372 & 216 & 361 & 198 \\
\hline & 112 & 167 & 118 & 169 & 118 & 167 \\
\hline & & 75 & & 85 & & 89 \\
\hline & & 25 & & $\mathrm{nd}^{*}$ & & nd \\
\hline
\end{tabular}

*because they were smaller than the lower limit of detection

Table 4: Theoretical and actual fragment length of PCR products amplified with the 41F-Eco-R primer set and digested with Hhal and Haelll in E. coli.

from K-12 and O157:H7 were digested with HhaI, and fragments of 118 and 361 bp in K-12 and 118 and 372 bp in O157:H7 were obtained, respectively, indicating that the PCR products were derived from each E. coli cDNA (Figures 3B and 4B). The same fragments derived from both $E$. coli cDNA were also observed after HaeIII digestion (Figures $3 \mathrm{C}$ and $4 \mathrm{C}$ ). These results were also similar to those obtained with MeRFLP of 41F-1066R primer set. In addition to the identification by RFLP, the results of MeRFLP were useful for detecting and reducing the rate of false positives, and thus reducing the chance of PCR bias. The MeRFLP analysis using PCR products obtained from cDNAs was specific in its identification of bacterial species, suggesting that the RTMeRFLP method can specifically detect viable $E$. coli cells.

Generally traditional detection methods including culture technique are time-consuming (requiring at least few days) [5]. Furthermore, the PCR-based sequencing analysis of bacterial identification is necessary for around 7 hours. Therefore, it takes it more than 12 hours before all from a sample preparation to bacterial identification is over. It took about 6.5 hours for the data collection, including sample preparation, using RT-MeRFLP, in which first RNA extraction is followed by identification by MeRFLP. This result demonstrates that the RT-MeRFLP method is a simple method and promising approach for overcoming the limitations in identifying viable bacterial contamination in food samples faster than the general methods involving cultivation and sequencing. When the target gene of the PCR primer sets for the RT-MeRFLP was altered in stx1 and stx2 or oriC [5,31], other pathogens such as E. coli O157:H7 (STEC) or Salmonella spp. could be detected without cultivation.

In the present study, bacterial RNA from food samples that had been inoculated with bacterial cells could be extracted without cultivation, and we then synthesized the cDNA and amplified the target gene from those RNAs. In other words, even when the purity of the extracted RNA was quite low, the RT of these RNAs for the synthesis of cDNA and use in PCR for MeRFLP could be achieved. In addition to the low RNA purity, other inhibitory factors of PCR could also be ignored in the E. coli detection with the new primer set, 41F-Eco-R. The RT-MeRFLP method should provide effective identification of target bacteria and detection of false-positive results. The method developed using the cDNA-based RT-MeRFLP without cultivation may provide an inexpensive bacterial identification system that will allow the rapid and reliable detection of pathogenic microorganisms directly in food. In addition to using the $16 \mathrm{~S}$ rRNA gene for the target bacteria, the addition of other primer sets to amplify specific bacteria may allow the detection and identification of diverse foodborne pathogens such as S. aureus, Salmonella spp., Campylobacter jejuni, and Vibrio parahaemolyticus $[32,33]$. Therefore, from a quality control perspective, this advanced cDNA-based MeRFLP method plays an important role in quality control inspection as well as monitoring in food industries because this advanced cDNA-based MeRFLP method can detect not only the food borne viable bacteria but also dead cells at each phase of the production process.

\section{Acknowledgements}

We thank Akiko Taneda and Akiko Ito for technical assistance. This work was supported in part by Aichi Science and Technology Foundation (The Knowledge Hub of AICHI, Nagoya, Japan)

\section{References}

1. Morin NJ, Gong Z, Li XF (2004) RReverse transcription-multiplex PCR assay for simultaneous detection of Escherichia coli O157:H7, Vibrio cholerae O1, and Salmonella Typhi. Clinical chemistry 50: 2037-2044.

2. Tanaka H, Kaneda F, Suguro R, Baba H (2004) Current system for regulation of health foods in Japan. Jap Med Assoc J 47: 436-440.

3. Hill WE (1996) The polymerase chain reaction: applications for the detection of foodborne pathogens. Cr Rev Food Sci 36: 123-173.

4. Blackstone GM, Nordstrom JL, Vickery MC, Bowen MD, Meyer RF, et al. (2003) Detection of pathogenic Vibrio parahaemolyticus in oyster enrichments by real time PCR. J Microbiol Methods 53: 149-155.

5. Fusco V, Quero GM (2012) Nucleic Acid-Based Methods to Identify, Detect and Type Pathogenic Bacteria Occurring in Milk and Dairy Products. In Tech. New York: 371-404.

6. Sheridan GEC, Masters Cl, Shallcross JA, Mackey BM (1998) Detection of mRNA by reverse transcription-PCR as an indicator of viability in Escherichia coli cells. Appl Environ Microbiol 64: 1313-1318.

7. Lee, JL Levin RE (2009) A comparative study of the ability of EMA and PMA to distinguish viable from heat killed mixed bacterial flora from fish fillets. $J$ Microbiol Methods 76: 93-96.

8. Soejima T, Minami J-i, Yaeshima T, Iwatsuki K (2012) An advanced PCR method for the specific detection of viable total coliform bacteria in pasteurized milk. Appl Environ Microbiol 95: 485-497.

9. Giebler J, Wick LY, Chatzinotas A, Harms H (2013) Alkane-degrading bacteria at the soil-litter interface: comparing isolates with T-RFLP-based community profiles. FEMS Microbiol Ecol 86: 45-58.

10. Tiedje JM, Asuming-Brempong S, Nüsslein K, Marsh TL, Flynn SJ (1999) Opening the black box of soil microbial diversity. Appl Soil Ecol 13:109-122.

11. Guan LL, Hagen KE, Tannock GW, Korver DR, Fasenko GM, et al. (2003) Detection and identification of Lactobacillus species in crops of broilers of different ages by using PCR-denaturing gradient gel electrophoresis and amplified ribosomal DNA restriction analysis. Appl Environ Microbiol 69: 6750 6757

2. Watanabe K, Okuda M, Koga N (2008) Newly developed system based on multiple enzyme restriction fragment length polymorphism - an application to proteolytic bacterial flora analysis. Soil Sci Plant Nutr 54: 204-215.

13. Hosoda A, Takahashi T, Numano K, Nakajou K, Higashimoto A, et al. (2012) Rapid Reductive Dechlorination of Trichloroethene in Contaminated Ground Water Using Biostimulation Agent, BD-1, Formulated from Canola Oil. J Oleo Sci 61: 155-161.

14. Fortuna A-M, Marsh TL, Wayne Honeycutt C, Halteman WA (2011) Use of primer selection and restriction enzymes to assess bacterial community diversity in an agricultural soil used for potato production via terminal restriction fragment length polymorphism. Appl Microbiol Biotechnol 91: 1193-1202.

15. Shigemori Y, Mikawa T, Shibata T, Oishi M, (2005) Multiplex PCR: use of heat-stable Thermus thermophilus RecA protein to minimize non-specific PCR products. Nucleic Acids Res 33: 126.

16. Bekaert B, Coomans M, Knaepen K, Larno L, Thijs N, et al. (2009) Validation of a microchip electrophoresis system as a DNA amplification control. Forensic Science International: Genetics Supplement Series 2: 119-120. 
Citation: Hosoda A, Komaba A, Kishimoto M, Tamura H (2013) Combination of Reverse Transcription and Multienzyme Restriction Fragment Length Polymorphism Analysis for Rapid Detection of Escherichia Coli. J Microb Biochem Technol 6: 001-008. doi:10.4172/1948-5948.1000113

17. Vincze T, Posfai J, Roberts RJ (2003) NEBcutter: a program to cleave DNA with restriction enzymes. Nucleic Acids Res 31: 3688-3691

18. Watanabe K, Watanabe K, Kodama Y, Syutsubo K, Harayama S, (2000) Molecular characterization of bacterial populations in petroleum-contaminated groundwater discharged from underground crude oil storage cavities. Appl Environ Microbiol 66: 4803-4809.

19. Cole JR, Chai B, Marsh TL Farris, Ryan J, Wang Q, et al. (2003) The Ribosomal Database Project (RDP-II): previewing a new autoaligner that allows regular updates and the new prokaryotic taxonomy. Nucleic Acids Res 31: 442-443.

20. Maidak BL, Cole JR, Lilburn TG, Parker Jr CT, Saxman PR, et al. (2001) The RDP-II (ribosomal database project). Nucleic Acids Res 29: 173-174.

21. Zhang J, Madden TL, (1997) PowerBLAST: a new network BLAST application for interactive or automated sequence analysis and annotation. Genome Res 7: 649-656.

22. Wang P, Qi M, Barboza P, Leigh MB, Ungerfeld E, et al. (2011) Isolation of highquality total RNA from rumen anaerobic bacteria and fungi, and subsequen detection of glycoside hydrolases. Can J Microbiol 57:590-598.

23. McKillip J L, Jaykus L-A, Drake M (1998) rRNA Stability in Heat-Killed and UVIrradiated Enterotoxigenic Staphylococcus aureus and Escherichia coli O157: H7. Appl Environ Microbiol 64: 4264-4268.

24. Lee S, Kemp PF, (1994) Single-cell RNA content of natural marine planktonic bacteria measured by hybridization with multiple $16 \mathrm{~S}$ rRNA-targeted fluorescent probes. Limnol Oceanogr 39: 869-879.

25. Sharma VK (2006) Real-time reverse transcription-multiplex PCR for simultaneous and specific detection of $\mathrm{rbE}$ and eae genes of Escherichia coli O157: H7. Mol Cell Probe 20: 298-306.

26. Suzuki, MT, Giovannoni SJ (1996) Bias caused by template annealing in the amplification of mixtures of $16 \mathrm{~S}$ rRNA genes by PCR. Appl Environ Microbiol 62: 625-630.

27. Gutell RR, Larsen N, Woese CR (1994) Lessons from an evolving rRNA: 16 S and $23 S$ rRNA structures from a comparative perspective. Microbiol Rev 58 $10-26$.

28. Woese CR, Magrum LJ, Gupta R, Siegel RB, Stahl DA, et al. (1980) Secondary structure model for bacterial 16 S ribosomal RNA: phylogenetic, enzymatic and chemical evidence. Nucleic Acids Res 8: 2275-2294.

29. Ye J, Coulouris G, Zaretskaya I, Cutcutache I, Rozen S, et al. (2012) PrimerBLAST: a tool to design target-specific primers for polymerase chain reaction. BMC bioinformatics 13: 134 .

30. Burrell A, Foy C, Burns M (2011) Applicability of three alternative instruments for food authenticity analysis: GMO identification. Biotechnol Res Int 2011: 1-9.

31. Elizaquivel P, Aznar R (2008) A multiplex RTi-PCR reaction for simultaneous detection of Escherichia coli O157: H7, Salmonella spp. and Staphylococcus aureus on fresh, minimally processed vegetables. Food Microbiol 25: 705-713.

32. Hara-Kudo Y, Konuma H, Kamata Y, Miyahara M, Takatori K, et al. (2012) Prevalence of the main food-borne pathogens in retail food under the national food surveillance system in Japan. Food Addit Contam Part A: 1-9.

33. Hara-Kudo Y, Takatori K (2011) Contamination level and ingestion dose of foodborne pathogens associated with infections. Epidemiol Infect 139: 15051510 . 